\title{
Association of C5a/C5aR pathway to activate ERK1/2 and p38 MAPK in acute kidney injury - a mouse model
}

\author{
Zeying Zhang*
}

Institute of Food and Health, Wuchang Institute of Technology, Wuhan, Hubei, China

\begin{abstract}
Acute inflammation is accompanied by complement system activation and inflammatory cell accumulation. Acute kidney injury (AKI) is one of the common clinical symptoms, it is not clear whether complement system-mediated signaling pathway is involved. This study demonstrated that the expressions of complement C5a and C5a receptor (C5aR) protein in a mouse model with glycerol induced AKI were significantly increased, and the expression of inflammatory cytokines, such as $I L-1 \beta, I L-6$ and $T N F-\alpha$, were significantly higher than those in the blank control group. While C5aR antagonist (C5aRa) was added, western analyses for C5a and C5aR were reduced, meanwhile, qPCR and ELISA data showed that inflammatory cytokines also decreased significantly. In addition, preliminarily explored, the Mitogen-activated protein kinases (MAPKs) can be activated by the C5a/C5aR pathway in an AKI mouse model which showed that the C5a/C5aR pathway in a mouse model group activated ERK1/2 and p38, and the protein expression decreased when C5aRa was added. In conclusion, these results indicate that the C5a/C5aR pathway promotes renal pathogenesis by activating ERK1/2 and p38 expression and then affects the disease process, which has certain guiding significance for the subsequent clinical trial.
\end{abstract}

Keywords: Acute kidney injury; C5a/C5aR; $M A P K$

Received: 20 th August 2021; Accepted: $7^{\text {th }}$ December 2021; Published: $16^{\text {th }}$ December 2021

\section{Introduction}

AKI is a clinical syndrome caused by rapid decline of renal function in a short time brought along by various causes $(1,2)$. It is manifested as decreased glomerular filtration rate, accompanied by retention of nitrogen products such as creatinine and urea nitrogen, and disturbance of water, electrolyte and acid-base balance, so as to cause a series of pathophysiological changes (3). With the outbreak of severe acute respiratory syndrome coronavirus 2 (SARS-CoV-2), a plethora of evidence have demonstrated that
AKI is very common among patients with COVID-19 (coronavirus disease 2019), occurring in approximately more than $50 \%$ of ICU (intensive care unit) patients (4-8). The extremely high rates of mortality could be the development of distant organ injury (9). It should not be considered as a single disease (10), when AKI appears, the primary task is to determine the etiology as soon as possible.

The complement system can be activated in response to infection and tissue damage (11). Activating the complement components in plasma

\footnotetext{
* Corresponding author: Zeying Zhang, Institute of Food and Health, Wuchang Institute of Technology, Wuhan, Hubei, China. E-mail: qianyezzy@163.com
} 
and body fluids are involved in the regulation of virtually all phases of an acute inflammatory reaction, such as the $\mathrm{C} 5 \mathrm{a}$, which plays a pro-inflammatory role by interacting with the C5aR (12). Recently, a growing number of findings suggested that $\mathrm{C} 5$ a modulate inflammation might cause with chemotaxis, then produce great number of radical oxygen species (ROS), and it will further increase vascular permeability (13). Apart from the inflammation response, $\mathrm{C} 5 \mathrm{a}$ has been also reported to modulate a tumor growth and metastasis $(14,15)$, which can increase the activation of extracellular signal-regulated kinase, such as p38 and Akt, promoting the formation of tumor (16-18). Thus, abnormal expression of C5a may indicate an increased risk of disease in patients. Consequently, it is a priority to clarify the mechanism of $\mathrm{C} 5 \mathrm{a} / \mathrm{C} 5 \mathrm{aR}$ system in AKI associated signaling pathway.

MAPK has served as significant link for transmitting signals to the nucleus from the cell surface, meanwhile, various extracellular influences, such as stress or adhesion, neurotransmitters, cytokines, hormones, might activate this process $(19,20)$. Moreover, MAPKs consist of c-Jun, $\mathrm{N}$-terminal kinase (JNK), extracellular signal regulated kinase (ERK), and p38, which also play an important role in the regulation of some related inflammatory factors (21). Previous studies have demonstrated that there are several important signaling pathways which are involved in AKI-related cell death, such as MAPK-ERK pathway (22). In the present study, we have successfully established the AKI model in the mouse and utilized multiple techniques to clarify the regulation mechanism with the AKI.

\section{Materials and Methods}

In order to study the relation of $\mathrm{C} 5 \mathrm{a} / \mathrm{C} 5 \mathrm{aR}$ pathway and ERK1/2 and p38MAPK in acute kidney injury, a prospective cohort study was conducted in an animal model. All animals were fed freely, raised in a sterile environment and the study was approved by the Ethics committee of the Hubei Center for Disease Control and Prevention. The animal model of AKI and the treatment were carried out on a blank control group, a model group, a $\mathrm{C} 5 \mathrm{aRa}+$ model group, and a $\mathrm{C} 5 \mathrm{aRa}$ group. The antibodies used in western blot analysis were C5a (Santa Cruz, Sc-398247), C5aR (Santa Cruz, Sc-53788), ERK1/2 (Abcam, ab54230), p-ERK1/2 (Abcam, ab201015), p38 (CST, 9212) and p-p38 (CST, 9211). The protein concertation was measured with the BCA Protein Assay Kit (Beyotime, P0012S), immunofluorescent assay (IFA) was further studied with Cy3 or FITC-conjugated secondary antibodies. Histopathology examination for kidney injury and renal function were assessed by hematoxylin and eosin (H\&E) staining, electron microscopy, then an automatic biochemistry analyzer was used to detect the contents of blood urea nitrogen (BUN, Changchun Huili Biotech, C083) and serum creatinine (Changchun Huili Biotech, C074). Moreover, ELISA assay of cytokines IL- $1 \beta$, TNF $\alpha$, IL-6, and IL-10 production were studied according to the manufacturer's instructions (Elabscience Biotechnology, E-EL-M0037c, E-EL-M0049c, E-EL-M0044c, E-EL-M0046c).

Kidney tissues were obtained from treated mice, then the tissues were studied to detect total RNA and cDNA with quantitative real-time polymerase chain reaction (PCR).

\section{Animal model of glycerol induced AKI}

Male BALB/c mice around 6 weeks old with specific pathogen-free, weighing 18-22g, were obtained from the Hubei Center for Disease Control and Prevention.

All mice were randomly assigned to different groups: blank control, a model, a C5aRa+ model, and a C5aRa group. Each group comprised six mice. After $16 \mathrm{~h} \sim 24 \mathrm{~h}$ of water prohibition, the model group was injected with $50 \%$ glycerol in both hind limbs respectively, and the mice 
were then allowed to eat and drink freely, then sacrificed 3 days later. The $\mathrm{C} 5 \mathrm{aRa}+$ model group received intraperitoneal injection of $\mathrm{C} 5 \mathrm{aRa} 2 \mathrm{~h}$ before AKI modeling, and then the mice were free to eat and drink. In the C5aRa group, saline was injected two hours after C5aRa injection. Materials were harvested 3 days after injection. After the orbital blood was collected, the serum was obtained by centrifugation, and then the mice were sacrificed. The left kidney was taken for fixation and the right kidney was frozen for further experiments.

\section{Western blot analysis for C5a, C5aR, ERK1/2, p-ERK1/2, p38 and p-p38}

The whole protein of kidney tissues and cells were extracted by the commercial protein extraction kit with the corresponding process, and the contents of protein were measured by BCA assay kit. Then, a total of $20-50 \mu \mathrm{g}$ protein was separated by treating with electrophoresis on SDS - PAGE gels. After that, the above proteins were transferred to the membranes containing polyvinylidene difluoride. Subsequently, the membranes were sealed up 5\% nonfat dry milk, and then the primary antibody (at 1:500-1:1,000 dilution) was further added into buffers for incubation overnight at $4{ }^{\circ} \mathrm{C}$. After $12 \mathrm{~h}$, the secondary antibody (1:1,000 dilution) was treated for $2 \mathrm{~h}$. Western blot assay of proteins were detected by the ECL kit. The protein signals were quantified by scanning densitometry using a Fluor Chem Q System (Alpha Intech, CA, USA).

Immunofluorescent assay (IFA).

Before carrying out the immunofluorescent assay, samples were prepared by the following operation. First, tissue sections in paraffin were deparaffinized with Histo-Clear, then hydrated with an ethanol gradient, and were boiled for antigen retrieval. Next, the sections were incubated with the primary antibodies overnight at $4{ }^{\circ} \mathrm{C}$ after fixing with $5 \% \mathrm{IgG}$ - free BSA (Sigma-Al- drich, A7030) for $1 \mathrm{~h}$ at room temperature. Then, sections were washed with tris-buffered saline (TBS) and Tween 20 (TBST) several times. Finally, the tissues were stained with the secondary antibodies that conjugated $\mathrm{Cy} 3$ or FITC, kept at room temperature for $1 \mathrm{~h}$. Of note, the tissues were incubated with 1:1,000 DAPI in TBST for 5 min to colocalize cellular nuclei.

\section{Histopathology examination of the kidney}

Fresh kidneys were retrieved from mice and fast fixed in $10 \%$ formaldehyde. After $48 \mathrm{~h}$, these kidney tissues were placed into paraffin blocks, then sectioned at $5 \mu \mathrm{m}$. In order to observe the damage to the kidney, the tissue sections were stained with hematoxylin and eosin, then assessed under electron microscopy.

\section{Assessment of renal function}

In order to assess the renal function, blood was collected from the ocular venous plexus before the animals were euthanized. Then, blood was centrifuged at $3000 \mathrm{rpm}$ under $4^{\circ} \mathrm{C}$ for $15 \mathrm{~min}$. The contents of BUN and serum creatinine (CREA) were measured by an automatic biochemistry analyzer (Rayto, Chemray420).

\section{ELISA assay of cytokines IL-1ß, TNF $\alpha, I L-6$ and $I L-10$ production}

The contents of TNF- $\alpha$, IL- $1 \beta$, IL- 6 , and IL-10 in mice serum were tested by ELISA with standard process.

\section{Quantitative polymerase chain reaction (QPCR)}

Kidney tissues were retrieved from mice at the indicated time points, and the total RNA was obtained by a common Trizol, then it reverses transcribed into cDNA. Next, the obtained cDNA was treated with amplification by PCR. mRNA levels were then normalized by the housekeeping gene GAPDH. 


\section{Statistical analysis}

All statistical analyses were performed in GraphPad Prism version 6, as defined in the text and figure legends.

\section{Results}

\section{Excessive activation of C5a and C5aR in the kidney with glycerol induced AKI}

In order to explore the $\mathrm{C} 5 \mathrm{a} / \mathrm{C} 5 \mathrm{aR}$ pathway activated in a glycerol induced AKI mouse model, we established AKI model successfully in the mice. We set up four groups, such as blank control group, a model group, a $\mathrm{C} 5 \mathrm{aRa}+$ model group, and a $\mathrm{C} 5 \mathrm{aRa}$ group to detect the expression of $\mathrm{C} 5 \mathrm{a}$ and $\mathrm{C} 5 \mathrm{aR}$. Compared to the blank control, expressions of $\mathrm{C} 5 \mathrm{a}$ and $\mathrm{C} 5 \mathrm{aR}$ protein were significantly elevated in the kidney tissue of the AKI mice model (Figure 1A and B), while after treating with $\mathrm{C} 5 \mathrm{aRa}, \mathrm{C} 5 \mathrm{a}$, and $\mathrm{C} 5 \mathrm{aR}$, pro- tein levels were suppressed (Figure 1A and B ). In addition, these results were further confirmed by immunofluorescence microscopy (Figure $1 \mathrm{C})$.

\section{Blockade of the C5a/C5aR pathway attenuates kidney injury of mice with glycerol induced AKI}

Based on the above results, hematoxylin and eosin (HE) staining was performed to conduct pathological examination. It showed significant histopathological changes and cellular infiltration in the glycerol induced AKI mouse model compared to the blank control group, while adding $\mathrm{C} 5 \mathrm{aRa}$ reduces the functional damage (Figure 2A). MPO assay was performed and demonstrated that in the model group MPO activity was higher than in the blank control group, after $\mathrm{C} 5 \mathrm{aR}$ antagonist was added to the model group, MPO activity was decreased significantly as
A

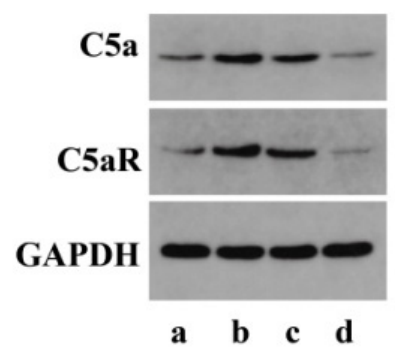

B

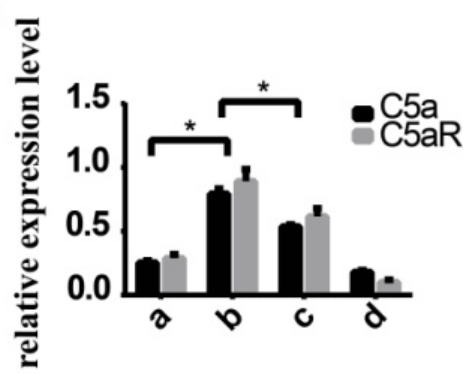

C
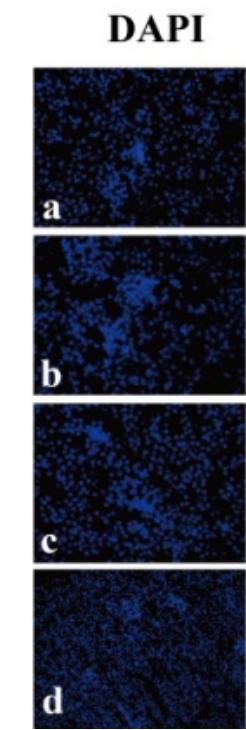

C5a
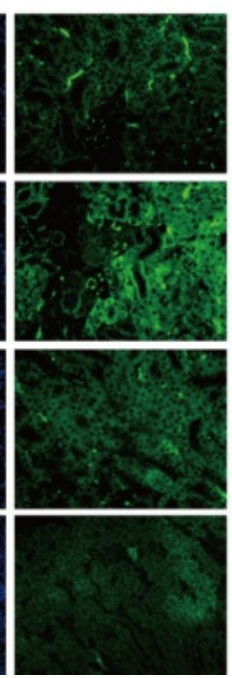

C5aR
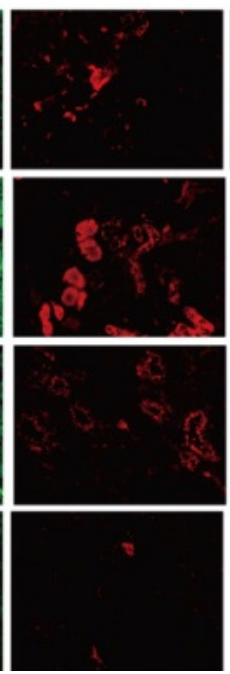

Merge

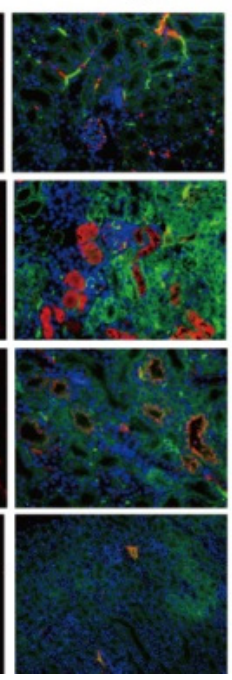

Fig. 1. Western blot (WB) and immunofuorescence of C5a and C5aR in each group of kidney tissue of mice with AKI, a, b, c and d represent blank (control) group, model group, C5aR+model group and C5aRa group. (A) WB of C5a and C5aR in a-d groups. (B) The ratio of C5a and C5aR to GAPDH. Values are expressed as the mean \pm SD. Asterisks denote significant differences by Student t-test analysis $(*$ for $P<0.05)$. (C) Immunofluorescence of C5a and C5aR in a-d groups. 
expected (Figure 2B). Subsequently, the levels of serum CREA and BUN were measured, and comparison was made between the four groups (Figure 2C). The results showed significant difference between the model group and the blank group, after adding $\mathrm{C} 5 \mathrm{aR}$ antagonist, the content of CREA and BUN reduced obviously as demonstrated in Figure 2C. All the results showed that $\mathrm{C} 5 \mathrm{aR}$ antagonist added can contribute to reduce the damage with AKI.

\section{The variation of pro-inflammatory cytokines

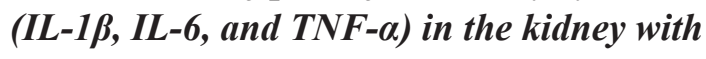 glycerol induced $A K I$}

In a glycerol induced AKI mouse model, tissue damage is severe. As such, inflammatory factors were measured, as demonstrated by a significant increase of pro-inflammatory cytokines in the serum (Figure $3 \mathrm{~A}$ and $\mathrm{B}$ ), such as IL- $1 \beta, \mathrm{TNF}-\alpha$, IL-6, and IL-10 were decreased. While treatment with C5aRa, all the mentioned pro-inflammatory cytokines were decreased, and anti-inflammatory cytokines IL-10 returned to normal level.

\section{C5a/C5aR pathway activated p38-MAPK and ERK1/2 during glycerol induced AKI} Previous studies have showed that C5a/C5aR activates multiple signaling proteins, including ERK and P13K (20). To explore whether the elevated expression of $\mathrm{C} 5 \mathrm{a} / \mathrm{C} 5 \mathrm{aR}$ can activate the MAPKs in glycerol induced AKI mouse model, we examined the effect of MAPK signaling pathway by using western blotting. Of note, p-p38 and p-ERK1/2 were detected in kidney tissue, which was significantly increased in the mouse model group, while decreased significantly after the addition of $\mathrm{C} 5 \mathrm{aR}$ antagonist (Figure 4A and B). This suggests that $\mathrm{C} 5 \mathrm{a} / \mathrm{C} 5 \mathrm{aR}$ pathway activates the MAPKs during glycerol induced AKI. Furthermore, we conducted tests at the cellular level. We set up five groups: blank group, model group, C5aRa + model group, ERK inhibitor + model group, and p38 inhibitor + model group. Among them, the contents of p-ERK $1 / 2$ and p-p38 in the five groups were all detected. As shown in the Figure $4 \mathrm{C}$ and D, there were significantly increased protein levels of $\mathrm{p}$-ERK $1 / 2$ and p-p38 in the model group when compared
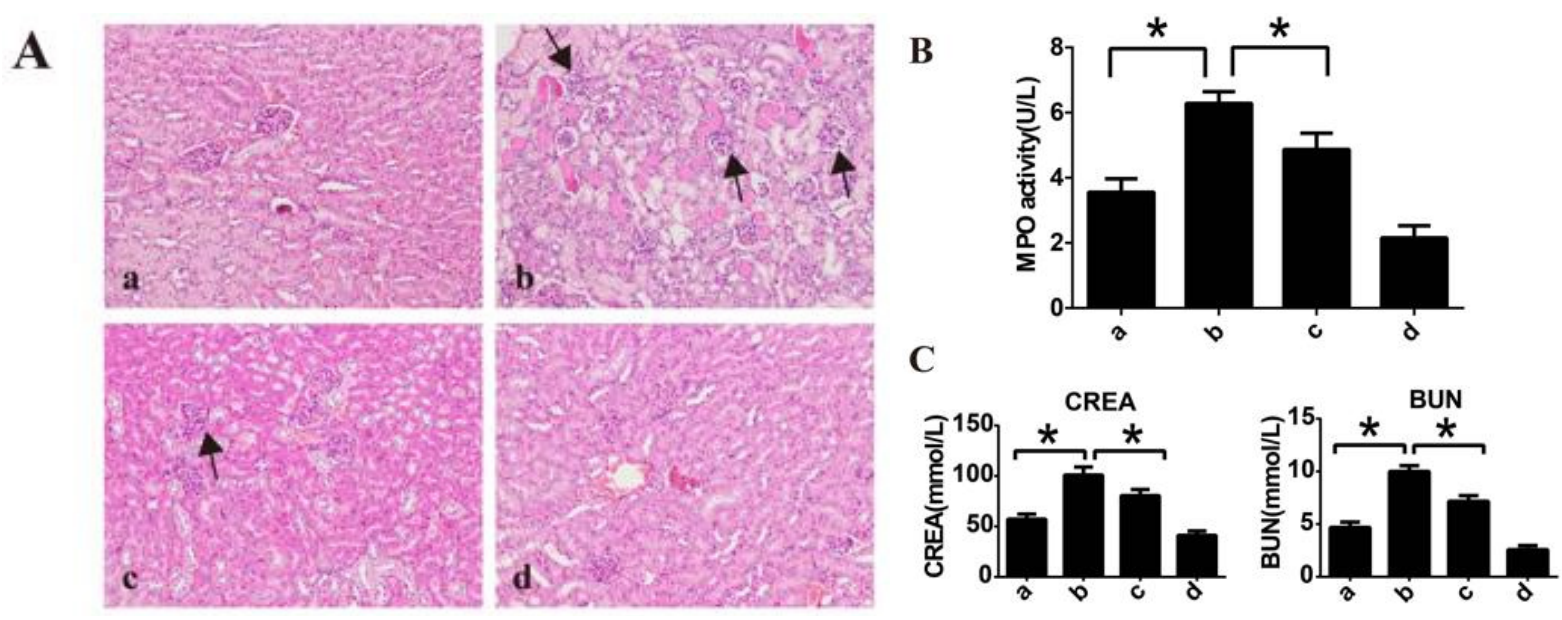

Fig. 2. H\&E staining and MPO activity assay for the kidney sections, a, b, c, d represent blank control group, model group, C5aRa+model group and C5aRa group. (A) H\&E staining, black arrows show infiltrations of neutrophil $(200 \times)$. (B) MPO activity assay for the kidney section. Data is from the mean of three biological replicates \pm SD, $p<0.05$. (C) Quanlification of serum CREA and BUN. Data is from the mean of three biological replicates $\pm \mathrm{SD}, \mathrm{p}<\mathbf{0 . 0 5}$. 
A
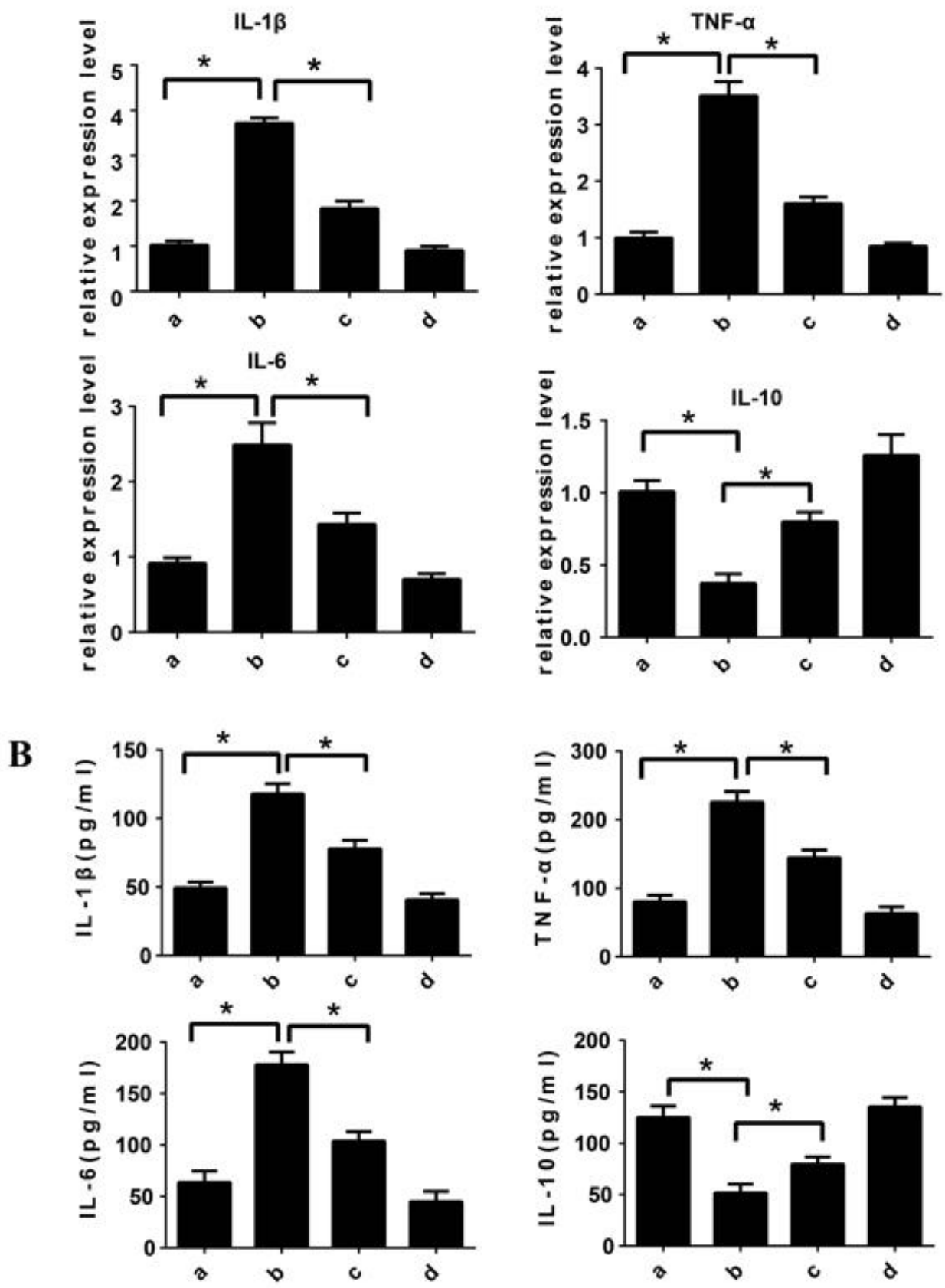

Fig. 3. QPCR and elisa data showed the expression of IL-1ß, IL-6 and TNF- $\alpha$ and IL-10 in the kidney with AKL, a, b, c, d represent blank control group, model group, C5aR+model group and C5aRa group. (A) Expression of IL-1 $\beta$, IL-6 and TNF- $\alpha$ and IL-10 mRNA in kidney tissue of four groups. Data is from the mean of three biological replicates \pm SD, $p<0.05$. (B) Serum levels of IL-1 $\beta$, IL-6 and TNF- $\alpha$ and IL-10 at 12 h. Data is from the mean of three biological replicates $\pm \mathrm{SD}, \mathrm{p}<0.05$. 


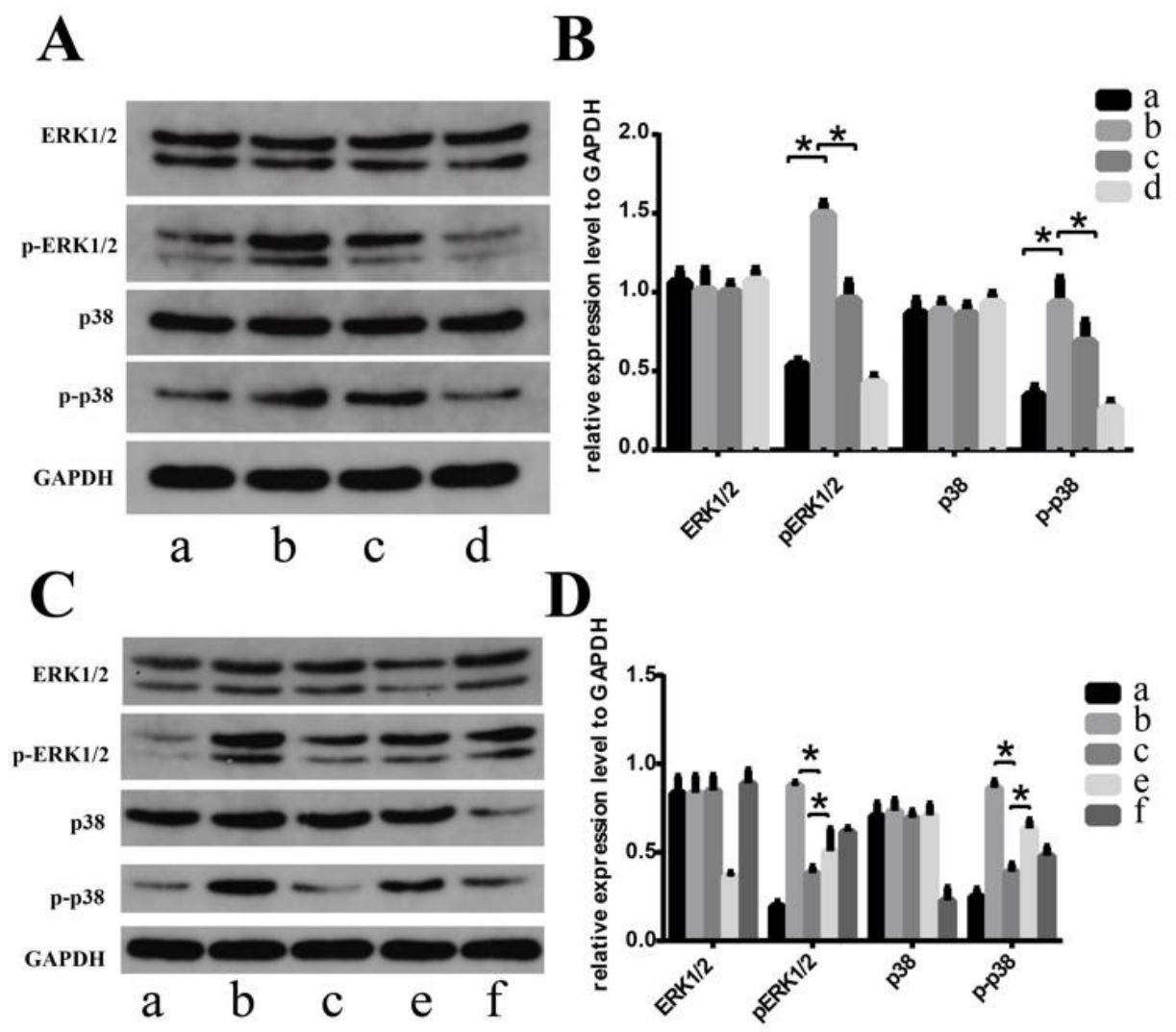

Fig. 4. ERK1/2, p-ERK1/2, p38 and p-p38 protein expressions in each group, a, b, c, d, e, f represent blank control group, model group, $\mathrm{C5aR}+$ model group, C5aRa group, ERK inhibitor group and $\mathrm{p} 38$ inhibitor group. (A) ERK1/2, p-ERK1/2, p38 and p-p38 protein expressions in the kidney tissues were detected by WB. (B) Results are expressed as the ratio of ERK1/2, p-ERK1/2, p38 and p-p38 with GAPDH, p<0.05. (C) ERK1/2, p-ERK1/2, p38 and p-p38 protein expressions in HK-2 cells detected by WB. (D) Results are expressed as the ratio of ERK1/2, p-ERK1/2, p38 and p-p38 with GAPDH, $p<0.05$.

to the blank control, which is consistent with the results showed in the kidney tissues of AKI mouse model (Figure 4A and B). When $\mathrm{C} 5 \mathrm{aR}$ antagonist was added, p-ERK1/2 and p-P38 returned to their normal level (Figure 4C and D). After ERK inhibitor or p38 inhibitor was added independently, the protein level returned to the normal level (Figure 4C and D). In conclusion, in the glycerol induced AKI mouse model, the $\mathrm{C} 5 \mathrm{a} / \mathrm{C} 5 \mathrm{aR}$ pathway is involved in the regulation of kidney injury by activating the downstream MAPK signaling pathway ERK1/2 and p38.

\section{Discussion}

Acute kidney injury is a complex critical disease accompanied by decrease in renal function and glomerular filtration rate that leads to the accumulation of creatinine, urea nitrogen, and other unmeasurable metabolic wastes in the body, causing a series of pathophysiological changes (21). In this study, in order to explore the pathogenesis of glycerol induced AKI, a glycerol induced AKI mouse model was successfully established. The WB results of kidney tissue showed that the protein level of $\mathrm{C} 5 \mathrm{a} / \mathrm{C} 5 \mathrm{aR}$ in the mouse 
model was significantly increased, and returned to the normal level after the addition of $\mathrm{C} 5 \mathrm{aR}$ antagonist (Figure 1A and B). Thus, we first proved that in the course of glycerol induced AKI, the $\mathrm{C} 5 \mathrm{a} / \mathrm{C} 5 \mathrm{aR}$ pathway is highly activated and involved in the regulation of AKI. A large number of references has reported that the activation of complement system induces a large number of inflammatory cytokines (25-27), which cause an inflammatory cytokine storm that plays a primary role in AKI $(28,29)$. As such, we measured the expression level of relevant cytokines. QPCR and ELISA data showed that TNF- $\alpha$, IL- 6 , and IL-1 $\beta$ accumulated, another anti-inflammatory cytokine, IL-10 decreased in the glycerol induced AKI mouse model (Figure 3A and B). The inflammatory cytokine storm was effectively alleviated when C5aRa was added (Figure 3A and $\mathrm{B})$. Therefore, based on the above results, our research demonstrated that $\mathrm{C} 5 \mathrm{a} / \mathrm{C} 5 \mathrm{aR}$ activation induced overproduction of inflammatory cytokines with the glycerol induced AKI. In addition, the previous studies have showed that there exist several critical signaling pathways involved in AKI-related cell death, such as PI3KAkt pathway, MAPK-ERK/JNK/p53 pathways, and AMPK-CREB pathway $(19,20)$. Thus, we want to explore the $\mathrm{C} 5 \mathrm{a} / \mathrm{C} 5 \mathrm{aR}$ pathway activation with glycerol induced AKI whether activated the MAPKs or not, WB was performed to detect the phosphorylation level of ERK1/2 and p38, which showed that in the mouse model group the expression of p-ERK1/2 and p-p38 protein significantly increased, while after adding C5aRa, protein expression of $p$-ERK1/2 and p-p38 returned to normal level (Figure 4A and B). Nevertheless, we did not perform further research to identify a marker gene which can predict glycerol induced AKI. Additionally, we do not have clinical patient samples for further research. In order to provide certain guiding significance for the subsequent clinical treatment of glycerol induced AKI, these problems need to be further explored.

\section{Conclusions}

In clonclusion, we first demonstrated that the $\mathrm{C} 5 \mathrm{a} / \mathrm{C} 5 \mathrm{aR}$ pathway increased kidney injury during glycerol induced AKI by activating ERK and p38 molecules in the MAPK signaling pathway, while treatment with $\mathrm{C} 5 \mathrm{aRa}$, the pathological symptoms of glycerol induced AKI can be alleviated. We conclude that C5a/C5aR signaling pathway plays a pivotal role in glycerol induced $\mathrm{AKI}$, interfering this pathway will become a promising therapeutic strategy in patients in the future.
Abbreviations
AKI: Acute kidney injury
IFA: Immunofluorescent assay
H\&E: Hematoxylin and eosin
BUN: Blood urea nitrogen
CREA: Serum creatinine
PCR: Polymerase chain reaction
ERK: Extracellular signal regulated kinase
JNK: c-Jun and N-terminal kinase

\section{Acknowledgments}

This work was supported by the Hubei Provincial Knowledge Innovation Special Fund of Natural Science Foundation (2018CFB696).

\section{Author Contributions}

ZYZ - Designing and carrying out all experiments; Funding acquisition; Writing - review and editing.

\section{Conflicts of Interest}

The authors declare no conflict of interest.

\section{References}

1. Gyal A, Daneshpajouhnejad P, Hashmi M. F, Bashir K. Acute Kidney Injury. In: StatPearls [Internet]. Treasure 
Island (FL): StatPearls Publishing; 2021 Jan; PMID: 28722925.

2. Ostermann M, Liu K. Pathophysiology of AKI. Best Pract Res Clin Anaesthesiol. 2017 Sep; 31(3):305-14. DOI: 10.1016/j.bpa.2017.09.001

3. Lande R. E, Blackburn R. Evaluating pharmacist training. Popul Rep J. 1989 Nov;(37):26-8.

4. Pei G, Zhang Z. Renal Involvement and Early Prognosis in Patients with COVID-19 Pneumonia. J Am Soc Nephrol. 2020 Jun; 31(6):1157-65. DOI: 10.1681/ ASN.2020030276

5. Chen T, Wu D, Chen H, Yan W, Yang D, Chen G, et al. Clinical characteristics of 113 deceased patients with coronavirus disease 2019: retrospective study. BMJ. 2020 Mar; 31(368):m1091. DOI: 10.1136/bmj.m1091

6. Zhou F, Yu T, Du R, Fan G, Liu Y, Liu Z, et al. Clinical course and risk factors for mortality of adult inpatients with COVID-19 in Wuhan, China: a retrospective cohort study. Lancet 2020 Mar; 395(10229):1054-62. DOI: 10.1016/S0140-6736(20)30566-3

7. Cao J, Tu WJ, Cheng W, Yu L, Liu YK, Hu X, et al. Clinical Features and Short-term Outcomes of 102 Patients with Coronavirus Disease 2019 in Wuhan, China. Clin Infect Dis. 2020 Jul; 71(15):748-55. DOI: 10.1093/cid/ciaa243

8. Hirsch JS, Ng JH, Ross DW, Sharma P, Shah HH, Barnett RL, et al. Acute kidney injury in patients hospitalized with COVID-19. Kidney Int. 2020 Jul; 98(1):20918. DOI: 10.1016/j.kint.2020.05.006

9. Nishida K, Watanabe H, Miyahisa M, Hiramoto Y, Nosaki H, Fujimura R, et al. Systemic and sustained thioredoxin analogue prevents acute kidney injury and its-associated distant organ damage in renal ischemia reperfusion injury mice. Sci Rep. 2020 Nov; 10(1):20635. DOI: 10.1038/s41598-020-75025-5

10. Nadim MK, Forni LG, Mehta RL, Connor MJ, Liu KD, Ostermann M, et al. COVID-19-associated acute kidney injury: consensus report of the 25th Acute Disease Quality Initiative (ADQI) Workgroup. Nat Rev Nephrol. 2020 Dec,16(12):747-74. DOI: 10.1038/ s41581-020-00356-5

11. Markiewski MM, Lambris JD. The role of complement in inflammatory diseases from behind the scenes into the spotlight. Am J Pathol. 2007 Sep;171(3):715-27. DOI: 10.2353/ajpath.2007.070166

12. Jeon H, Han SR, Lee S, Park SJ, Kim JH, Yoo SM, et al. Activation of the complement system in an os- teosarcoma cell line promotes angiogenesis through enhanced production of growth factors. Sci Rep. 2018 April; 8:5415. DOI: 10.1038/s41598-018-23851-Z

13. Liu XY, Wang XY, Li RY, Jia SC, Sun P, Zhao M, et al. Recent progress in the understanding of complement activation and its role in tumor growth and anti-tumor therapy. Biomed Pharmacother. 2017Jul; 91:446-56. DOI: 10.1016/j.biopha.2017.04.101

14. Afshar-Kharghan V. The role of the complement system in cancer. J Clin Invest. 2017 Mar; 127(3):780-9. DOI: $10.1172 / J C I 90962$

15. Schraufstatter IU, Trieu K, Sikora L, Sriramarao P, DiScipio R. Complement c3a and c5a induce different signal transduction cascades in endothelial cells. J Immunol. 2002 Aug; 169(10):2102-10. DOI: 10.4049/ jimmunol.169.4.2102

16. Monsinjon T, Gasque P, Chan P, Ischenko A, Brady JJ, Fontaine MC. Regulation by complement C3a and C5a anaphylatoxins of cytokine production in human umbilical vein endothelial cells. Faseb j. 2003 Jun;17(9):1003-14. DOI: 10.1096/fj.02-0737com

17. Rousseau S, Dolado I, Beardmore V, Shpiro N, Marquez R, Nebreda AR, et al. CXCL12 and C5a trigger cell migration via a PAK1/2-p38alpha MAPK-MAPKAP- K2-HSP27 pathway. Cell Signal. 2006 Nov; 18(11):1897-905. DOI: 10.1016/j.cellsig.2006.02.006

18. Markiewski MM, DeAngelis RA, Strey CW, Foukas PG, Gerard C, Gerard N, et al. The regulation of liver cell survival by complement. J Immunol. 2009 May; 182(9):5412-8. DOI: 10.4049/jimmunol.0804179

19. Albert-Gascó H, Ros-Bernal F. MAP/ERK Signaling in Developing Cognitive and Emotional Function and Its Effect on Pathological and Neurodegenerative Processes. Int J Mol Sci. 2020 Jun; 21(12):4471. DOI: 10.3390/ ijms21124471

20. El Rawas R, Amaral IM. Is p38 MAPK Associated to Drugs of Abuse-Induced Abnormal Behaviors? Int J Mol Sci. 2020 Jul; 21(14):4833. DOI:10.3390/ijms 21144833. DOI: 10.3390/ijms

21. Sun Y, Liu WZ, Liu T, Feng X, Yang N, Zhou HF. Signaling pathway of MAPK/ERK in cell proliferation, differentiation, migration, senescence and apoptosis. J Recept Signal Transduct Res. 2015 Jun; 35(6):600-4. DOI: 10.3109/10799893.2015.1030412

22. Davidson SM, Arjun S, Basalay MV, Bell RM, Bromage DI, Bøtker HE, et al. The 10th Biennial Hatter 
Cardiovascular Institute workshop: cellular protection-evaluating new directions in the setting of myocardial infarction, ischaemic stroke, and cardio-oncology. Basic Res Cardiol 2018 Oct; 113(6):43. DOI: 10.1007/ s00395-018-0704-z

23. Dong Q, Jie Y, Ma J, Li C, Xin T, Yang D. Renal tubular cell death and inflammation response are regulated by the MAPK-ERK-CREB signaling pathway under hypoxia-reoxygenation injury. J Recept Signal Transduct Res. 2019 Oct-Dec; 39(5-6):383-91. DOI: 10.1080/10799893.2019.1698050

24. Levey AS, James MT. Acute Kidney Injury. Ann Intern Med. 2017 Nov; 167(9):ITC66-80. DOI: 10.7326/ AITC201711070

25. Polycarpou A, Howard M, Farrar CA, Greenlaw R, Fanelli G. Rationale for targeting complement in COVID-19. EMBO Mol Med. 2020 Aug; 12(8):e12642. DOI: $10.15252 / \mathrm{emmm} .202012642$
26. Hammerschmidt DE, Weaver LJ, Hudson LD, Craddock PR, Jacob HS. Association of complement activation and elevated plasma-C5a with adult respiratory distress syndrome. Pathophysiological relevance and possible prognostic value. Lancet 1980 May; 1(8175):947-9. DOI: 10.1016/S0140-6736(80)91403-8

27. Rittirsch D, Flierl MA, Nadeau BA, Day DE, Huber-Lang M, Mackay CR, et al. Functional roles for C5a receptors in sepsis. Nat Med. 2008 May; 14(5):551-7. DOI: $10.1038 / \mathrm{nm} 1753$

28. Skausig O. B, Lversen O. Severe paresis caused by electrolyte disturbances following end-to-side jejunoileostomy for morbid obesity. Dan Med Bull. 1979 Nov;26(7):344-5.

29. Tsai JP, Lee CJ, Subeq YM, Lee RP, Hsu BG. Acute Alcohol Intoxication Exacerbates Rhabdomyolysis-Induced Acute Renal Failure in Rats. Int J Med Sci. 2017 Jun 23;14(7):680-9. DOI: 10.7150/ijms.19479. 